\title{
REGULASI PENGELOLAAN ZAKAT DI INDONESIA
}

\author{
Suprima \\ Fakultas Hukum Universitas Pembangaunan Nasional "Veteran" Jakarta \\ Email: suprima@upnvj.ac.id \\ Holilur Rahman \\ Institut Dirasat Islamiyah Al-Amien (IDIA) Sumenep \\ Email: holafif@gmail.com
}

\begin{abstract}
Abstrak
Penelitian ini bertujuan untuk mengkaji peran negara kepada kebolehan pengelola (amil) dalam pengelolaan dan pendistribusian zakat di Indonesia. Metode penelitian ini merupakan kualitatif. Pendekatan yang digunakan yuridis-normatif. Kemudian analisis data melalui hukum integratif yang menanamkan dimensi ketaatan dalam beragama (diyani) dan dimensi ketetapan dalam bernegara (qada'i) melalui regulasi zakat yang berlaku di Indonesia. Kemudian dianalisis melalui metode diskriptif analitis. Kemudian hasil penelitian ini membuktikan bahwa negara mempunyai peran yang sangat penting dalam mengelola, memanajemen, dan mengedepankan kemakmuran dan kemaslahatan dengan memberikan peluang pengelolaan atau manajemen zakat melalui regulasi atau hubungan zakat tentang kebolehan amil zakat dalam pengambilan, pemungutan, dan pendistribusiannya.
\end{abstract}

Kata Kunci: regulasi, kebolehan, amil, diyani, qada'i.

\begin{abstract}
This study aims to examine the role of the state in the ability of managers (amil) in the management and distribution of zakat in Indonesia. This research method is qualitative. Juridical-normative approach. Then the data analysis through integrative law that instills the dimension of obedience in religion (diyani) and the dimension of determination in the state (qada'i) through the regulation of zakat in force in Indonesia. Then analyzed through descriptive analytical methods. Then the results of this study prove that the state has a very important role in managing, managing, and promoting prosperity and benefit by providing opportunities for management or management of zakat through zakat regulation or relationship regarding the acquisition of amil zakat in its collection, collection and distribution.
\end{abstract}

Keywords: regulation, permits, amil, diyani, qada'i.

\section{A. PENDAHULUAN}

\section{Latar Belakang Masalah}

Muara perkembangan zakat dengan hadirnya regulasi zakat. Saat ini regulasi zakat berupa UU No. 23/2011 tentang pengelolaan zakat, Peraturan Pemerintah Republik 
Indonesia nomor 14 tahun 2014 tentang pelaksanaan undang-undang nomor 23 tahun 2011 tentang pengelolaan zakat, kemudian Instruksi Presiden Republik Indonesia nomor 3 tahun 2014 tentang optimalisasi pengumpulan zakat di Kementerian/Lembaga, Sekretariat Jenderal Lembaga negara, Sekretariat Jenderal komisi negara, Pemerintah Daerah, Badan Usaha Milik Negara, dan Badan Usaha Milik Daerah melalui Badan Amil Zakat Nasional serta berbagai Peraturan Daerah tentang zakat. Ini berarti bahwa pengelolaan zakat memiliki penguatan dalam pengumpulan maupun kelembagaan.

Usaha memahami produk hukum harus dipelajari bagaimana terjadinya teks, diketahui keterangannya dan dalam suasana apa teks tersebut dibuat. Dengan demikian dapat dimengerti maksud Undang-Undang dan aliran yang menjadi dasar UndangUndang. Berdasarkan naskah akademis, dan Sambutan Akhir Pemerintah pada Rapat Paripurna DPR dalam rangka pengambilan keputusan terhadap RUU tentang Pengelolaan Zakat, ada empat dasar yang menjadi dasar pemikiran yang menjiwai lahirnya rumusan pasal-pasal dan bunyi ayat dalam UU No. 23/2011 tentang pengelolaan zakat, yakni: ${ }^{1}$

Pertama, mewujudkan sistem terpadu (unified system) dalam manajemen atau pengelolaan zakat. Kegiatan pengambilan atau pengumpulan zakat, penyaluran dan pemberdayaan zakat di Indonesia harus terintegrasi dengan Badan Amil Zakat Nasional (BAZNAS). Badan Amil Zakat Nasional (BAZNAS) didesain sebagai executive agency (lembaga eksekutif) pemerintah dalam pemungutan atau pengelolaan zakat.

Relasi agama dan negara yang integral dijadikan dasar dalam pengurusan zakat. Allah memerintahkan pemungutan zakat kepada amil zakat atau pemerintahan yang sah

${ }^{1}$ DPR RI, "Risalah Rapat”, Pembahasan Rancangan Undang-Undang tentang Pengelolan Zakat, dalam naskah akademis dan Sambutan Akhir Pemerintah pada Rapat Paripurna DPR dalam rangka pengambilan keputusan terhadap RUU tentang Pengelolaan Zakat 2011. Bandingkan dengan M. Fuad Nasar, Zakat di Ranah Agama dan Negara (Jakarta: Rafikatama, 2017), 39. 
sesuai dengan QS. Al-Taubah (9) ayat 103 dengan mengangkat dan mengutus para amil zakat untuk melaksanakan tugasnya.

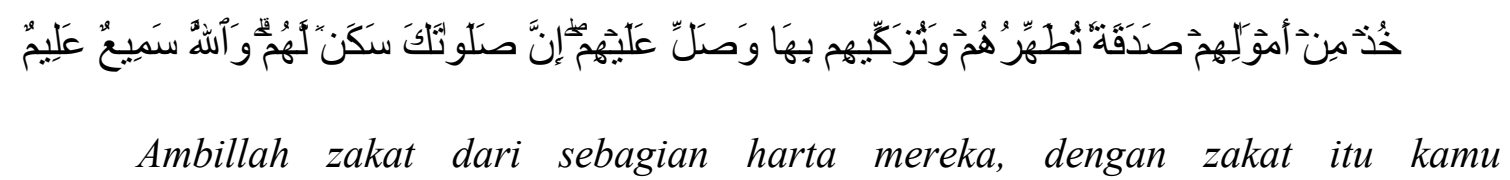
membersihkan dan mensucikan mereka dan mendoalah untuk mereka. Sesungguhnya doa kamu itu (menjadi) ketenteraman jiwa bagi mereka. Dan Allah Maha Mendengar lagi Maha Mengetahui. (Q.S. At-Taubah (9): 103).

Latar belakang teologis dan historis itu melatarbelakangi pemikiran untuk merumuskan diktum pasal dalam Undang-Undang. Dipahami bahwa setiap orang yang bertindak selaku amil melakukan pengelolaan zakat wajib mendapatkan izin pejabat yang berkuasa/berwenang. Sebaliknya ancaman pidana bagi setiap individu dengan sengaja bertindak sebagai amil tanpa izin pejabat yang berkuasa/berwenang.

Kedua, hierarki dalam manajemen atau pengelolaan zakat. Manajemen zakat dilaksanakan secara bertahap atau berjenjang oleh pengelola atau amil zakat. Badan Amil Zakat Nasional (BAZNAS) pusat dan daerah serta Lembaga Amil Zakat (LAZ) merupakan satu kesatuan organisasi yang memiliki hubungan hierarkis. Perubahan fundamental lahirnya UU No. 23/2011 yang berisi tentang pengelolaan atau manajemen zakat yang menyangkut hubungan Badan Amil Zakat Nasional (BAZNAS) dan Lembaga Amil Zakat (LAZ) di semua tingkatan yang bersifat hierarkis. Bentuk hierarki dalam pengelolaan zakat tergambarkan dalam alur pelaporan dan pertanggungjawaban pengelola zakat kepada Badan Amil Zakat Nasional (BAZNAS) dan dari BAZNAS kepada Presiden melalui Menteri Agama Republik Indonesia dan kepada Dewan Perwakilan Rakyat Republik Indonesia (DPR RI) sekali dalam setahun. 
Ketiga, kepatuhan atau pemenuhan (cimpliance) pada ketentuan syariat. Prinsip syariat Islam dikukuhkan sebagai dasar pertama dalam urutan dasar pengelolaan atau manajemen zakat. Prinsip itulah yang melatarbelakangi adanya klausul bahwa untuk mendapat izin sebagai Lembaga Amil Zakat (LAZ) harus memenuhi persyaratan teregister sebagai organisasi sosial kemasyarakatan Indonesia yang mengatur bidang dakwah, pendidikan, dan sosial kemasyarakatan yang berbentuk institusi berbadan hukum. Pertimbangannya adalah pengelolaan zakat tidak dapat dilakukan oleh lembaga berbadan hukum di luar umat Islam. Bahwa zakat sebagai norma dasar atau pokok yang diatur oleh undang-undang yang merupakan ranah agama sebagaimana yang diatur dalam syariat Islam.

Keempat, akuntabilitas (accountability) pengelolaan zakat. Manajemen atau pengelolaan zakat hakikatnya adalah pekerjaan amanah yang harus dilaksanakan oleh

amil zakat. Pengelolaan zakat menuntut akuntabilitas yang terpercaya pada institusi pengelolanya. Oleh karena itu, prinsip akuntabilitas menjadi kunci berhasil atau tidak kepercayaan yang diberikan oleh muzaki untuk didayagunakan dan didistribusikan kepada para ashnaf.

\section{Rumusan Masalah}

Berdasarkan permasalahan di atas, penulis dapat merumuskan masalah sebagai berikut:

Bagaimana signifikansi regulasi zakat dalam mengatur pengelolaan zakat di Indonesia? 


\section{B. PEMBAHASAN}

\section{Literatur Review}

Pembahasan regulasi zakat sangat menjadi perhatian mengingat pengelolaan zakat merupakan rukun Islam. Dengan demikian, tentunya menjadi pusat pengkajian para ustadz, kyai, dan ulama. Di dalam fikih zakat (serapan dari kata fiqh dalam bahasa arab), Al Qur'an dan Hadits selalu ditemukan pengkajian tentang zakat. Salah satu dari di antara fikih zakat yang dianggap lengkap, dengan bahasan menyeluruh/komprehensif dan relevan dengan keadaan saat ini adalah karya Yusuf Al-Qaradawi yang berjudul Fiqh al-Zakah. ${ }^{2}$

Secara historis penjelasan hukum tentang zakat dari zaman Belanda sampai sekarang masih relevan dikaji. Hal tersebut dapat dibaca dalam tulisan Arskal Salim yang berjudul The Influential Legacy of Dutch Islamic Policy on The Formation of Zakat (Alms) Law in Modern Indonesia (Warisan yang Berpengaruh dari Kebijakan Islam Belanda tentang Pembentukan Hukum Zakat di Indonesia Modern) $)^{3}$. Tulisan tersebut menerangkan bahwa dampak kebijakan Islam Belanda sudah mengalami pengurangan secara berjenjang seiring perkembangan Islamisasi yang telah terjadi di negara republik Indonesia.

Pada mula abad ke-19, C. Snouck Hurgronje memiliki peran yang sangat penting dalam kebijakan (policy) zakat pada masa Belanda, yang memiliki tujuan pencegahan (preventive) hukum tentang wajib zakat.

Kemudian perkembangan pengelola (amil) zakat dapat dibaca dalam tulisan Asep Saepudin Jahar yang berjudul Marketing Islam Through Zakat Institutions in

\footnotetext{
II, $660-680$

${ }^{2}$ Yusuf al-Qaradawi, Fiqh al-Zakah (Bayrut: al Risalah al 'Alamiyah, 2009), Juz I, 660-620, Juz

${ }^{3}$ Arskal Salim, "The Influential Legacy Of Dutch Islamic Policy On The Formation Of Zakat (Alms) Law In Modern Indonesia," Pacific Rim Law and Policy Journal 15. No. 3, (2006), 9.
} 
Indonesia (Pemasaran Islam Melalui Lembaga Zakat di negara Indonesia) ${ }^{4}$. Tulisan tersebut membuktikan bahwa fakta Lembaga Zakat seperti Dompet Dhu'afa kemunculan dan praktiknya berlangsung bukan sebagai karakteristik dari proses Islamisasi. Akan tetapi model pendekatan yang dikerjakan lebih tepat dengan model atau gaya pemasaran Islam. ${ }^{5}$

Kemudian penelitian yang ditulis Palmawati Taher yang memiliki judul Zakat and Country Study of the Process of Zakat in Improving Community Welfare with the Applicability of Law Number 38 of 1999 concerning Management of Zakat (Zakat dan Negara Studi Tentang Proses Zakat dalam Meningkatkan Kesejahteraan Masyarakat dengan Berlakunya Undang-Undang Nomor 38 tahun 1999 tentang Pengelolaan Zakat). ${ }^{6}$ Penelitian tersebut mengkaji secara filosofis akan tetapi dalam penelitian tersebut tidak mengkaji bagaimana mekanisme pemungutan, pengambilan atau pengumpulan dana zakat.

Kemudian dapat dibaca dalam Tulisan Farah Aida Ahmad Nadzri, Normah Omar dan Rashidah Abd. Rahman yang memiliki judul Zakat and Poverty Alleviation: Roles of Zakat Institutions in Malaysia (Zakat dan Pengentasan Kemiskinan: Peran Lembaga Zakat di Malaysia). ${ }^{7}$ Menerangkan bahwa pengelola (amil) zakat berkuasa atau berwenang memungut, mengambil atau mengumpulkan zakat kemudian menyalurkan kepada orang yang berhak menerimanya (mustahik). Syarat wajib zakat erat

\footnotetext{
${ }^{4}$ Asep Saepudin Jahar, "Marketing Islam through Zakat Institutions in Indonesia," Studia Islamica Journal 22, No. 3 (2015): 405.

${ }^{5}$ yaitu menawarkan pemberdayaan zakat di masyarakat untuk kepentingan ekonomi, sosial dan kemanusiaan bagi kepentingan kelompok miskin dan tidak mampu.

${ }^{6}$ Palmawati Taher, Zakat dan Negara Studi tentang Proses Zakat dalam Meningkatkan Kesejahteraan Masyarakat dengan Berlakunya Undang-Undang Nomor 38 tahun 1999 tentang Pengelolaan Zakat, Disertasi Doktor (Depok: Perpustakaan FH. UI, 2004).

${ }^{7}$ Farah Aida Ahmad Nadzri, Rashidah Abd. Rahman, and Normah Omar, "Zakat and Poverty Alleviation: Roles of Zakat Institutions in Malaysia", International Journal of Arts and Commerce Vol.1 No. 7, (2012), 71.
} 
hubungannya dengan ide kesejajaran dan keadilan dalam ajaran Islam. Tujuan yang terpenting dari zakat ialah mengayomi, memberikan kesejahteraan masyarakat fakir miskin supaya mengangkat martabat kehidupan yang baik. Dipercayakan zakat terhadap pengelola (amil) zakat menjadikan pola penyaluran atau pendistribusian zakat ke sektor yang lebih produktif. Terdapat cara pengelola (amil) zakat sehingga dapat bekerjasama dan berkontribusi dengan lembaga sosial kemasyarakatan supaya pengelolaan atau manajemen zakat lebih efektif dan efisien dalam menyelesaikan persoalan atau kasus manusia (SDM), minimnya pengelola (amil) dan minimnya para pakar di bidangnya.

Kemudian karya Saidurrahman diberi judul The Politics of Zakat Management in Indonesia; The Tension Between BAZ and LAZ (Politik Pengelolaan Zakat di Indonesia; Ketegangan Antara Badan Amil Zakat (BAZ) dan Lembaga Amil Zakat (LAZ), ${ }^{8}$ menerangkan bahwa dinamisnya perdebatan lembaga pengelola (amil) zakat yang dilahirkan/didirikan pemerintah Badan Amil Zakat Nasional (BAZNAS) dengan yang didirikan/dilahirkan oleh masyarakat Lembaga Amil Zakat (LAZ). Salah satu di antaranya dengan cara terpusat atau terpadu dalam memanajemen zakat yang diberikan kewenangan atau kuasa kepada Badan Amil Zakat Nasional (BAZNAS). Padahal kinerja Badan Amil Zakat Nasional (BAZNAS) masih dipermasalahkan mengenai perolehan pemungutan, pengambilan, pengumpulan zakat oleh Lembaga Amil Zakat (LAZ) lebih besar dari pada Badan Amil Zakat Nasional (BAZNAS) pada tahun 2011. Dengan demikian pentingnya ada hubungan yang memberikan peluang atau ruang yang lebih maksimal kepada pengelola (amil) zakat supaya dapat dikelola menjadi lebih baik.

Berbeda jika dibandingkan dengan penelitian di atas, Robert D. McChesney mengatakan Islam tidak mempunyai pola pengelolaan atau manajemen zakat. Hal

\footnotetext{
${ }^{8}$ Saidurrahman, "The Politics of Zakat Management in Indonesia; The Tension Between BAZ and LAZ", Journal of Indonesian Islam, Volume 07, Number 02, (2013).
} 
tersebut tergambarkan dari munculnya keragaman pengelolaan atau manajemen zakat yang diselaraskan dengan kondisi serta situasi.

Dapat juga dibaca dalam buku Charity and Philantropy in Islam: Institutionalizing the Call to Do Good (Pekerjaan Amal dan Filantropi dalam Islam: Melembagakan Panggilan untuk Melakukan yang Baik), ${ }^{9}$ menyatakan Islam tidak mempunyai pola pengaturan pengelola (amil) zakat bisa dikelola oleh lembaga sosial masyarakat.

Sebagian yang lain memfokuskan pada dimensi historis filantropi Islam di Indonesia, misal yang ditulis oleh Azyumardi Azra yang berjudul "Filantropi dalam Sejarah Islam di Indonesia". ${ }^{10}$ Dinamika perzakatan di masa kolonial secara umum dipengaruhi oleh nasihat C. Snouck Hurgronce (1857-1936), dalam judul NasihatNasihat C. Snouck Hurgronce Kepegawaiannya terhadap Pemerintah Hindia Belanda, ${ }^{11}$ nasihat Snouck paling berpengaruh terhadap bentuk pengelolaan zakat, biaya pernikahan dan wakaf. Menurutnya di wilayah Nusantara zakat telah melembaga di tengah masyarakat. Namun penekanan keharusan zakat dan benda yang dikeluarkan atau dibayarkan zakatnya berbeda pada satu tempat dengan tempat yang lain. Menurutnya sifat zakat sukarela dan tidak seperti pajak.

Kajian yang senada dilakukan oleh Amelia Fauzia yang berjudul, Filantropi Islam Sejarah dan Kontestasi Masyarakat Sipil dan Negara di Indonesia. ${ }^{12}$ Buku ini merupakan hasil pengembangan dari disertasinya yang berjudul Faith and The State: a

\footnotetext{
${ }^{9}$ Robert D. McChesney, Charity and Philantropy in Islam: Institutionalizing the Call to Do Good (Indianapolis: Indiana University enter on Philantropy, 1993).

${ }^{10}$ Azyumardi Azra, "Filantropi dalam Sejarah Islam di Indonesia" dalam Zakat dan Peran Negara, ed. Kuntoro Noor Aflah, dan Mohd. Nasir Tanjung (Jakarta: Foorum Zakat, 2006), 15-30.

${ }^{11}$ E. Gobee dam C. Andrianse, Nasihat-Nasihat C. Snouck Hurgroce Kepegawaiannya Kepada Pemerintah Hindia Belanda 1889-1936 (Jakarta: INIS, 1992), 1357-1365.

${ }^{12}$ Amelia Fauzia, Filantropi Islam Sejarah dan Kontestasi Masyarakat Sipil dan Negara di Indonesia (Yogyakarta: Gading, 2016)
} 
History of Islamic Philanthropy in Indonesia (Iman dan Negara: Sejarah Filantropi Islam di negara Indonesia). ${ }^{13}$ Tulisan yang lebih spesifik berdasarkan pendekatan historis menyatakan bahwa Islam tidak memiliki pola pengaturan pengelola (amil) zakat yang ditulis oleh Muchtar Sadili yang memiliki judul Relevansi Zakat Terhadap Civil Society. (masyarakat sipil). ${ }^{14}$

Kemudian penelitian (riset) Said Abdullah Syahab yang memiliki judul Negara vs Masyarakat dalam Pengelolaan Zakat (Analisis al-Maslahah di Indonesia (Countries vs Communities in Management of Zakat (Analysis of al-Maslahah in Indonesia). ${ }^{15}$ Riset tersebut merupakan kualitatif dengan pendekatan deskriptif analitis. Data penelitian tersebut diambil dari pendalaman riset kepustakaan dengan membahas konsep al-maslahah dalam mengambil rumusan manajemen zakat yang lebih baik dan efektif dalam suatu negara terkhusus negara Indonesia. Selanjutnya menganalisis dinamika perkembangan politik dan sosial kemasyarakatan yang berkaitan dengan kebijakan politik (political policy) dan peran masyarakat sipil (civil society) di wilayah Indonesia dalam kaitannya dengan pengoptimalisasian manajemen zakat di negara Indonesia.

\section{Hasil Pembahasan}

Mengkaji tentang peran negara dalam hal mengelola atau manajemen zakat bagian bentuk hubungan agama dan negara yang menyatukan negara dan agama. Paradigma simbiotik (saling menguntungkan) dalam hubungan atau relasi negara dengan agama memberikan hak atau kebolehan pengumpulan atau pemungutan zakat kepada Badan Amil Zakat Nasional (BAZNAS) di Indonesia. Sehingga negara dan

\footnotetext{
${ }^{13}$ Amelia Fauzia, Faith and The State: a History of Islamic Philanthropy in Indonesia, Disertasi (Melbourne: The Asia Institute, The University of Melbourne, 2008).

${ }^{14}$ Lihat http://grops.yahoo.com/gropfilantropy_indonesia/message/2632. diakses 15 April 2016.

${ }^{15}$ Said Abdullah Syahab, Negara Versus Masyarakat Dalam Pengelolaan Zakat (Analisis alMaslahah di Indonesia) (Jakarta: UIN Syarif Hidayatullah 2014).
} 
agama walaupun dua hal yang tidak sama, akan tetapi keduanya saling berkolaborasi dan melengkapi. Dengan maksimalnya pengelolaan zakat tuntutan agama dalam menjalankan ibadah bisa terlaksana dengan benar dan baik, terkhusus dalam hubungannya menjaga harta (hifzul maal) sebagai tujuan syariat (maqasid al-shari'ah) dalam agama Islam. Oleh karenanya, peranan negara dalam ajaran Islam dijalankan sebagai bentuk aktualisasi syariah.

Adanya peran negara terhadap pengelolaan zakat secara filosofi dianalisis melalui teori diyani-qad'i (agama dan negara). Berdasarkan analisis teori diyani-qada'i, hukum zakat sebagai bagian dari hukum Islam dapat menjadi salah satu sumber hukum nasional. Hal ini mengingat dimensi yang terkandung dalam pengelolaan zakat memuat: 1) perintah ibadah yang syarat dengan ritual-muamalah; 2) ajaran yang pelaksanaannya tidak hanya urusan pribadi tetapi menyangkut hubungan masyarakat dan negara; 3) kewenangan amil yang menyangkut hak dan kewajiban muzaki-mustahik; 4) efektivitas pelaksanaannya tergantung amil zakat. Dengan demikian, hukum zakat menjadi hukum nasional karena entitas zakat mengandung integrasi agama dan negara.

Secara aplikatif bentuk peran negara terintegrasi terhadap amil zakat dengan ditetapkannya regulasi zakat. Sehingga regulasi zakat memiliki signifikansi sebagai esensial hak atau kebolehan amil dalam mengelola zakat dengan berusaha menjadikan tujuan bernegara dalam Undang-Undang Dasar Republik Indonesia (UUD RI) tahun 1945 yakni mengedepankan kemakmuran dan kemaslahatan umum. Kemudian konstitusi berusaha melaksanakan tujuan bernegara dengan memberi jaminan orang fakir, miskin dan orang terlantar diurus, dipelihara, dan diperhatikan oleh negara. Dengan menjamin orang yang fakir, miskin dan orang terlantar merupakan dari tujuan ekonomi nasional dan kesejahteraan sosial bagi seluruh rakyat Indonesia. Oleh 
karenanya, melalui undang-undang nomor 23/2011 yang berisi tentang pengelolaan atau manajemen zakat dan turunan perundang-undangan yang lainnya menginformasikan atau menunjukkan penerapan keberpihakan dan peranan negara dalam upaya menjadikan tujuan negara sesuai dengan konstitusi yang berlaku di negara Indonesia.

Berdasarkan uraian di atas, maka pengkajian tentang tema regulasi zakat tentang kewenangan atau kebolehan pengelola (amil) zakat di negara Indonesia terkhusus yang berkaitan dengan institusi atau kelembagaan dan hasil pengelolaan serta pemungutan atau pengambilan yang dilakukan amil zakat berbeda dengan penelitian yang dilakukan sebelumnya. Oleh karenanya, dianggap relevan dan memiliki peluang terbuka untuk dibahas atau diteliti lebih mendalam kemudian diintegrasikan dengan peraturan perundang-undangan yang berlaku di Indonesia.

\section{METODOLOGI}

Riset ini ditulis dengan metode yuridis-normatif. ${ }^{16}$ Dengan demikian penelitian yuridis normatif berdasar pada analisis norma hukum, baik hukum dalam pengertian hukum yang tertulis (ius constitutum) atau kitab-kitab agama atau ius constituendum maupun hukum seperti yang diputuskan oleh hakim melalui jalur proses peradilan. ${ }^{17}$

\section{Objek dan jenis Penelitian}

\footnotetext{
${ }^{16}$ Penelitian hukum normatif adalah penelitian hukum yang meletakkan hukum sebagai sebuah bangunan sistem norma. Penelitian hukum normatif dapat juga disebut dengan penelitian hukum kepustakaan, yang mencakup: (1) penelitian terhadap asas-asas hukum, (2) penelitian terhadap sistematik hukum, (3) penelitian terhadap taraf sinkronisasi vertikal dan horizontal, (4) perbandingan hukum, (5) sejarah hukum. Soejono Soekanto dan Sri Mamudji, Penelitian Hukum Normatif (Jakarta: Raja Grafindo Perkasa, 2010), 13-14.

${ }^{17}$ Ronald Dworkin, Legal Research (Deadalus: Spring, 1973),250. Lebih lanjut baca tulisan Sotandyo Wignjosoebroto, Hukum Paradigma, Metode dan Dinamika Masalahnya (Jakarta: ELSAM \& HUMA, 2002), 139-178
} 
Objek penelitian dari pembahasan ini adalah dasar-dasar, norma dan tujuan hukum $^{18}$ yang memiliki keterkaitan dengan pengelola (amil) zakat. Adapun jenis penelitian ini ialah penelitian pustaka (library research). ${ }^{19}$ Penelitian ini kualitatif. ${ }^{20}$ Penelitian yang bersifat kualitatif ini digunakan untuk mengkaji lebih mendalam tentang kewenangan dan kebolehan amil zakat dalam mengoptimalkan atau memaksimalkan institusi atau kelembagaan melalui regulasi pengelolaan atau manajemen zakat.

\section{Pendekatan Penelitian}

Pendekatan penelitian yang digunakan ada dua pendekatan yakni: Pertama, pendekatan perundang-undangan (statute approach). Kedua, pendekatan historis dan interpretatif. $^{21}$

\section{Sumber data}

Sumber data penelitian ini dikategorisasikan pada beberapa bahan hukum, yakni; pertama, bahan hukum pokok atau $\operatorname{primer}^{22}$ yang akan diteliti meliputi sumber utama Islam berupa nash Al-Quran dan Hadis serta ijtihad atau pendapat para ahli fikih dan tafsir hukum (fuqaha). Bahan hukum pokok atau primer lainnya ialah produk lembaga legislatif Dewan Perwakilan Rakyat Republik Indonesia seperti Undang-Undang Nomor 23 tahun 2011 yang berisi tentang pengelolaan zakat, Peraturan Pemerintah Nomor 14

\footnotetext{
${ }^{18}$ Soerjono Soekanto dan Sri Mamudji, Penelitian Hukum Normatif (Jakarta: Raja Grafindo Perkasa, 2007), 15.

${ }^{19}$ Sumadi, Merode Penelitian (Jakarta: Rajawali Press, 1998), 19.

${ }^{20}$ Robert Bogdan dan Steven j, Taylor, Introduction to Qualitativ Research Method (New York: John Wily \& Sons, 1975)., Sugiyono, Metode Penelitian Kuantitatif Kualitatif dan R\&D (Bandung: Alfabeta, 2010), 24.

${ }^{21}$ Originally referring to the interpretation of religious text, Jurgen Habermas (1971) and others have adapted the process of hermeneutics to understand of social life. Earl Babbie, The Practice of Social, ed., (Belmont: Wadsworth Publishing Company, 1998), 281.

${ }^{22}$ Bahan hukum primer merupakan bahan hukum yang bersifat otoritatif artinya mempunyai otoritas. Lihat Peter Mahmud Marzuki, Penelitian Hukum (Jakarta: Prenada Media, 2006), 141. Bahan hukum primer, yaitu bahan-bahan hukum yang mengikat, dan terdiri atas: (1) Norma dasar atau kaidah dasar, yaitu Pembukaan UUD 1945, (2) Peraturan dasar, pasal-pasal UUD RI tahun1945 dan Tap MPR, (3) Peraturan perundang-undangan, (4) Bahan hukum yang tidak dikodifikasikan, seperti hukum adat, (5) Yurisprudensi, (6) Traktat, (7) Bahan hukum dari zaman penjajahan yang masih berlaku, seperti Kitab Undang-Undang Hukum Pidana. Soejono Soekanto dan Sri Mamudji, Penelitian Hukum Normatif, Op. Cit., h. 13.
} 
tahun 2014, Instruksi presiden Nomor 3 tahun 2014 serta berbagai peraturan daerah tentang zakat. Kedua, bahan hukum pendukung atau sekunder ${ }^{23}$ yang diteliti dan ditelaah meliputi buku-buku teks (taxt book), buku tentang sejarah Islam, jurnal tentang zakat, majalah, hasil riset seperti tesis dan disertasi, serta data resmi institusi yang berhubungan dengan lembaga pengelola (amil) zakat. Ketiga, bahan hukum tersier ${ }^{24}$ yang digunakan meliputi kamus, ensiklopedia, dan Indeks Zakat Nasional yang ada di Indeonesia.

\section{Teknik Pengumpulan Data}

Teknik pengumpulan data dalam riset ini dilakukan melalui dokumentasi. Teknik dokumentasi dilaksanakan untuk mengumpulkan data sekunder. Kemudian teknik dokumentasi dilaksanakan untuk mengkaji dan menelaah data yang berupa dokumen penting yang berhubungan dengan aspek riset baik dalil agama, maupun peraturan undang-undang. Kemudian peneliti memanfaatkan beberapa dokumen seperti, risalah sidang, buku, majalah, fatwa, laporan-laporan, keputusan-keputusan tentang zakat dan sebagainya.

\section{Teknik Analisis Data}

Peran negara dalam mengatur kebolehan pengelola (amil) dianalisis melalui teori hukum integratif yang menanamkan atau menginternalisasikan dimensi ketaatan dalam beragama (diyani) dengan menjalankan perintah atau ajaran agama dan juga dimensi ketetapan negara $\left(q a d a^{\prime} i\right)$ yang berlaku di Indonesia. Data tersebut kemudian dianalisis atau diinterpretasikan secara kualitatif dengan metode analitis deskriptif.

\footnotetext{
${ }^{23}$ Bahan hukum sekunder memberikan penjelasan mengenai bahan hukum primer, seperti, rancangan Undang-Undang, hasil penelitian, dan seterusnya.

${ }^{24}$ Bahan hukum tersier, yaitu bahan yang memberikan petunjuk maupun penjelasan terhadap bahan hukum primer dan sekunder; contohnya adalah kamus, ensiklopedia, indeks kumulatif, dan seterusnya.
} 


\section{SIMPULAN}

Transformasi atau internalisasi hukum Islam menjadi sebuah hukum positif bisa efektif bila mana memiliki esensi yang mengikat dari hukum Islam (agama) yang bersifat keimanan dan ketuhanan. Indonesia sebagai negara hukum menjadikan norma agama sebagai sumber dalam hukum nasional. Agama dan negara berintegrasi dalam kepentingan kesejahteraan masyarakat. Agama memberikan solusi terhadap negara melalui zakat, dan negara mengintervensi agama melalui regulasi zakat. Dengan demikian agama dan negara melakukan hubungan simbiotik. Jadi signifikansi regulasi zakat dalam rangka mengoptimalkan peran negara dalam memajukan kesejahteraan umum.

\section{DAFTAR PUSTAKA}

Badan Amil Zakat Nasional (BAZNAS). Outlook Zakat Indonesia 2017. Jakarta: PUSKAS BAZNAS, 2017.

Dworkin, Ronald. Legal Research. Deadalus: Spring, 1973.

Fauzia, Amelia. Faith and The State: a History of Islamic Philanthropy in Indonesia. Melbourne: The Asia Institute, The University of Melboure, 2008. , Filantropi Islam Sejarah dan Kontestasi Masyarakat Sipil dan Negara di Indonesia. Yogyakarta: Gading, 2016.

Gobee, E. \& C. Andrianse, Nasihat-Nasihat C. Snouck Hurgroce Kepegawaiannya Kepada Pemerintah Hindia Belanda 1889-1936. Jakarta: INIS, 1992.

Jahar, Asep Saepudin. "Marketing Islam through Zakat Institutions in Indonesia." Studia Islamica Journal. Vol. 22, No. 3. 2015.

Marzuki, Peter Mahmud. Penelitian Hukum. Jakarta: Prenada Media, 2006.

McChesney, Robert D. Charity and Philantropy in Islam: Institutionalizing the Call to Do Good. Indianapolis: Indiana University enter on Philantropy, 1993.

Miftah, A.A. Zakat Sebagai Hukum Diyani dan Qada"i, Disertasi. Jakarta: UIN Syarif Hidayatullah Jakarta, 2005. 
Muftie, Aries. "Optimalisasi Pengumpulan Zakat", dalam Zakat dan Peran Negara. Jakarta: FOZ, 2006.

Nadzri, Farah Aida Ahmad Rashidah Abd. Rahman, and Normah Omar. "Zakat and Poverty Alleviation: Roles of Zakat Institutions in Malaysia", International Journal of Arts and Commerce Vol.1 No. 7. 2012.

al-Qarad $\}$ a $>$ wi $>$, Yu $>$ suf. Fiqh. al-Zaka $>$ h. Juz I, II. Bayru>t: al Risa>lah al 'Alamiyah, 2009.

Saidurrahman, "The Politics of Zakat Management in Indonesia; The Tension Between BAZ and LAZ", Journal of Indonesian Islam, Volume 07, Number 02. 2013.

Salim, Arskal "The Influential Legacy Of Dutch Islamic Policy On The Formation Of Zakat (Alms) Law In Modern Indonesia," Pacific Rim Law and Policy Journal 15. No. 3.2006.

Seokanto dan Sri Mamudji. Penelitian Hukum Normatif. cet. 13. Jakarta: Raja Grafindo Persada, 2011.

Syahab, Said Abdullah. Negara Versus Masyarakat dalam Pengelolaan Zakat (Analisis al-Maslahah di Indonesia). Jakarta: UIN Syarif Hidayatullah, 2014.

Taher, Palmawati. Zakat Dan Negara Studi Tentang Proses Zakat Dalam Meningkatkan Kesejahteraan Masyarakat Dengan Berlakunya UU No. 38 tahun 1999 tentang Pengelolaan Zakat. Disertasi Doktor. Depok: Perpustakaan FH. UI, 2004.

Widyawati. Filantropi Islam dan Kebijakan Negara Pasca Orde Baru: studi tentang Undang-Undang Zakat dan Undang-Undang Wakaf, Disertasi. Jakarta: UIN Syarif Hidayatullah, 2011.

Wignjosoebroto, Sotandyo. Hukum Paradigma, Metode dan Dinamika Masalahnya. Jakarta: ELSAM \& HUMA, 2002.

Yani, Dwi. Strategi Penghimpunan Dana Zakat oleh BAZNAS, Tesis. Jakarta: PSTTIUI, 2008.

Yaqin, Anwarul. Legal Research and Writing. Selangor: LexisNexis, 2007.

http://grops.yahoo.com/gropfilantropy_indonesia/message/2632. diakses 15 April 2016. www.bps.go.id. 